\title{
Integrating GIS technologies in hydro power plant cascade simulation model
}

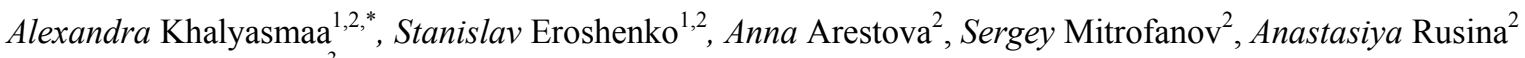 \\ and Alexey Kolesnikov ${ }^{3}$ \\ ${ }^{1}$ Ural Federal University, Ural Power Engineering Institute, Ekaterinburg, Russia \\ ${ }^{2}$ Novosibirsk State Technical University, Faculty of Power Engineering, Novosibirsk, Russia \\ ${ }^{3}$ Siberian State University of Geosystems and Technologies, Department of Cartography and Geoinformatics, Novosibirsk, Russia
}

\begin{abstract}
The paper presents the calculation algorithm for water-energy regime of a hydroelectric power plants cascade. The block diagram of the algorithm is given for implementing the simulation model and automating the process of calculating the regime. The proposed algorithm allows to evaluate the efficiency of the cascade, as well as to optimize the regime according to various criteria. Additionally, an option is proposed for integrating GIS monitoring data into the calculation algorithm.
\end{abstract}

\section{Introduction}

Simulation modeling is a research method in which the system involved is replaced by a model that describes the real system with sufficient accuracy (the model describes the processes as they would be in reality), with which experiments are conducted in order to obtain information about this system.

Simulation modeling, at present, has become widespread and is presented in diverse types of studies: business processes, population dynamics, traffic, rail transportation, market and competition, healthcare, engineering and many others. If the control object is a hydro power plant (HPP) cascade, process modeling should take into account not only various control algorithms for this facility, but also changing input parameters driven by natural conditions.

In the theory of simulation modeling, three main methods are distinguished: discrete event modeling, agent modeling and system dynamics. For complex systems involved, multi-approach models can be used.

HPPs are complex, artificially created open-type systems with specific properties: the probabilistic nature of parameters that change over time, close relationships with social, economic, and natural factors. The complexity of the production process, the duration of operation and the variability of the natural factors impact during the year make it urgent to create a simulation model of a HPP. The simulation model allows replacing full-scale tests, "playing over" and analyzing many states, adjustment of operating modes [1].

The authors elaborated a simulation model that combines the hydraulic and electric modes of the electric power system [2]. When modeling the operating modes and status of the HPP reservoir, it is important to use reliable statistical information. Actual input information, as well as its short-term and long-term forecast can be obtained on the data of territory spatial monitoring system, technologies of geoinformation modeling.

Often, data from ground-based surveillance tools are costly, and provide an insufficient coverage area (both in territorial and temporal aspects) [3]. The optimal solution would be the use of earth remote sensing (ERS). As a rule, earth remote sensing data refer to satellite images obtained from man-made Earth satellites that have undergone processing and are a raster image of the Earth's surface, as well as a spatial image data file [4]. ERS data are available for any territory and, accordingly, for any existing or planned HPP. An additional advantage is that this information with the accuracy sufficient for scientific research is freely available. ERS data can be used in conditions where ground-based research methods are impossible, for example, mountainous terrain, remote areas, glacial drifts, etc. ERS data are used as the basis for geographic information systems (GIS).

\section{ERS opportunity analysis}

Herewithin it is necessary to evaluate the possibilities of ERS by applicability in calculating the regime of a HPP cascade and also narrow down the list of possible source data to the most significant parameters for the simulation model. The scheme for integrating GIS technologies into the simulation model is presented in Figure 1.

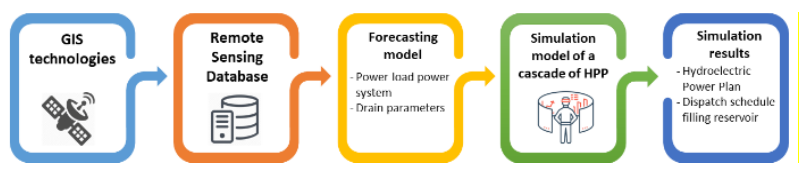

Fig. 1. Integration of GIS technologies into the simulation model of a HPP cascade

Corresponding author: lkhalyasmaa@mail.ru 
Conventionally, ERS data relevant to the described problem can be divided into two categories: geographical and climatic. The first category includes:

1. Relief geometric parameters. Based on a digital relief model, using geographic information systems, a number of derived parameters can be obtained that comprehensively describe a specific place on the Earth's surface [5] (Figure 2):

- slope - a value that determines the steepness of the relief and representing the maximum variability coefficient of the current cell of the digital relief model, relative to neighboring cells. It is taken into account, for example, when calculating the water flow speed;

- exposure - the direction of the cardinal directions in which the plane of the slope is oriented for each cell of the digital relief model. Most often it is taken into account when determining the amount of sunlight received by this part of the slope, or the flow direction;

- curvature - a value indicating the degree of concavity or convexity of the surface, which is used in calculating the position of the catchment areas;

- topographic position index (TPI) - the calculated complex value of the excess index, which allows to determine the characteristics and classify watersheds, slopes and relief elements.

Given the study object, these parameters are important in assessing:

- volume of water in the river network;

- flow direction;

- provisions of areas in case of precipitation;

- estimated amount of melting snow based on its position relative to the prevailing direction of solar irradiation.

2. Hydrographic objects geometric parameters. These include: water-surface area and the width of the dam site.

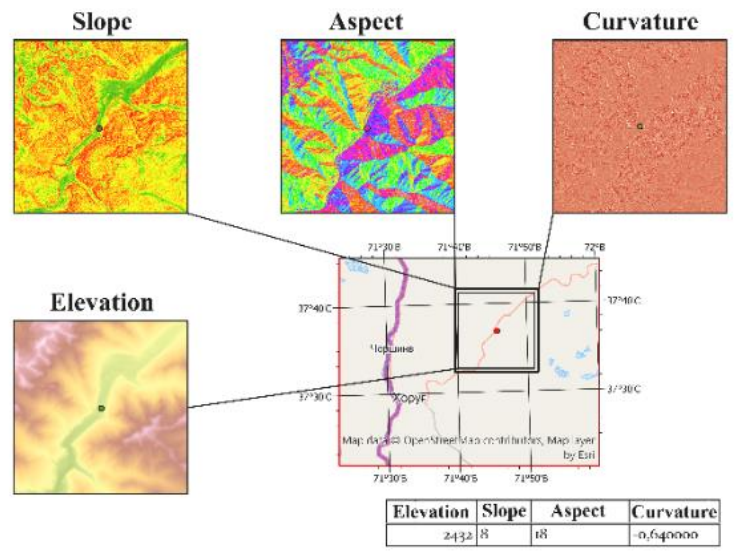

Fig. 2. Example of visualization of terrain parameters
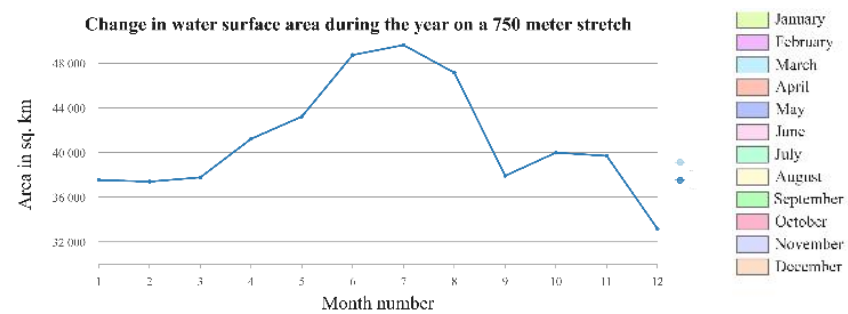

Fig. 3. Visualization of changes in the water-surface area
The geometrical parameters of hydrographic objects are subject to change and will depend on the date of the study. To calculate geometrical parameters, it is necessary to select the boundaries of hydrographic objects on satellite images by manually indicating the contour, or by automatically selecting pixels based on some automated decryption algorithm (Figure 3).

The parameters of the geographical group are basic. By combining them, an additional system of hydrological parameters will be obtained (watercourses, flow directions and cumulative flow points, catchment areas), which can also be used to construct a simulation model of the HPP cascade.

The second category includes:

1. Temperature. Two options can be used in the calculations - the air temperature obtained from meteorological stations and the earth's surface temperature obtained from satellite images based on thermal spectral channels [6, 7] (Figure 4).

2. Precipitation intensity based on microwave radiometry [8-10].

3. Quantitative indicators of the snow cover of the territories forming the runoff of the analyzed river - the snow cover surface and its thickness, based on the indirect parameter of the water equivalent (Figure 5). These indicators are important for medium and longterm forecasting $[11,12]$.

A summary of possible source data is given in Tables 1 and 2. It should also be noted that since all the parameters described above are based on raster representation data, the resolution is indicated for a basic assessment of their planned accuracy.

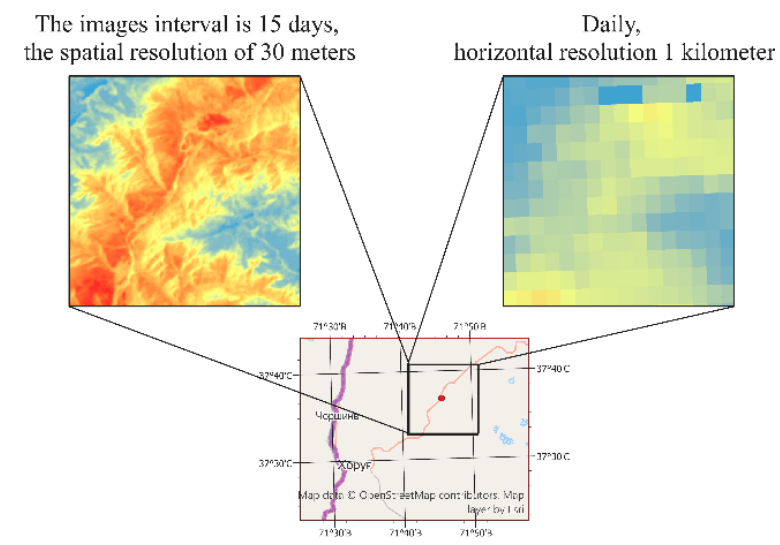

Fig. 4. Visual presentation of data on the earth's surface temperature of the same area for different time resolutions.
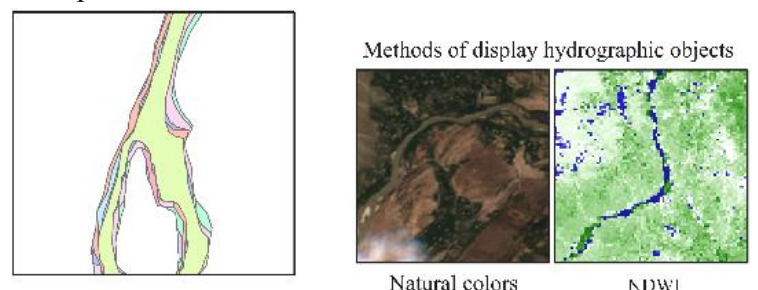


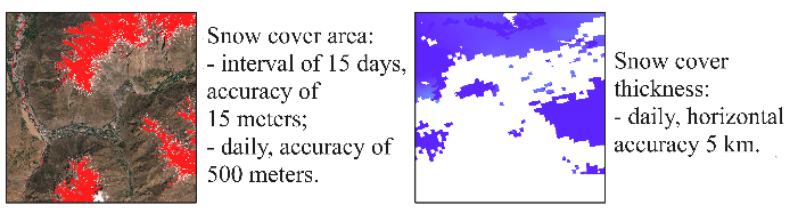

Fig. 5. Visualization of snow cover data for the same territory.

Table 1. Summary table of benchmarks sources.

\begin{tabular}{|c|c|c|c|}
\hline Group & Indicator & Measuring units & Source \\
\hline \multirow{7}{*}{ 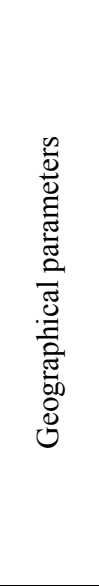 } & $\begin{array}{l}\text { Actual } \\
\text { elevation }\end{array}$ & Meters & $\begin{array}{l}\text { Alos Palsar } \\
\text { Sentinel S1A }\end{array}$ \\
\hline & Slope & $\begin{array}{l}\text { Degrees or } \\
\text { percent }\end{array}$ & $\begin{array}{l}\text { Alos Palsar } \\
\text { Sentinel S1A }\end{array}$ \\
\hline & Exposure & $\begin{array}{l}\text { Azimuth in } \\
\text { degrees }\end{array}$ & $\begin{array}{l}\text { Alos Palsar } \\
\text { Sentinel S1A }\end{array}$ \\
\hline & Curvature & $\begin{array}{l}\text { Curvature } \\
\text { coefficient in the } \\
\text { range of values } \\
\text { from }-4 \text { to }+4\end{array}$ & $\begin{array}{l}\text { Alos Palsar } \\
\text { Sentinel S1A }\end{array}$ \\
\hline & TPI & $\begin{array}{l}\text { Relief type } \\
\text { classes }\end{array}$ & $\begin{array}{l}\text { Alos Palsar } \\
\text { Sentinel S1A } \\
\end{array}$ \\
\hline & $\begin{array}{l}\text { Water-surface } \\
\text { area }\end{array}$ & Square meters & $\begin{array}{l}\text { Sentinel-2 } \\
\text { Landsat } 8 \\
\end{array}$ \\
\hline & Dam site width & Meters & $\begin{array}{l}\text { Sentinel-2 } \\
\text { Landsat } 8\end{array}$ \\
\hline \multirow{4}{*}{ 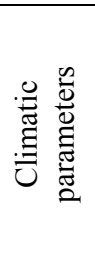 } & $\begin{array}{l}\text { Earth's surface } \\
\text { temperature }\end{array}$ & Degrees Celsius & $\begin{array}{l}\text { MODIS } \\
\text { Landsat } 8\end{array}$ \\
\hline & $\begin{array}{l}\text { Precipitation } \\
\text { rate }\end{array}$ & Mm / hour & REMSS \\
\hline & Snow cover & Square meters & $\begin{array}{l}\text { MODIS } \\
\text { Sentinel-2 }\end{array}$ \\
\hline & Snow depth & $\mathrm{Mm}$ & Copernicus \\
\hline
\end{tabular}

Table 2. A summary table of benchmarks characteristics.

\begin{tabular}{|c|c|c|c|}
\hline Group & Indicator & $\begin{array}{c}\text { Resolution, } \\
\text { meters }\end{array}$ & Update interval \\
\hline \multirow{7}{*}{ 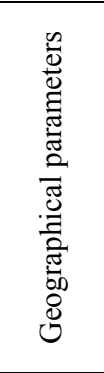 } & $\begin{array}{l}\text { Actual } \\
\text { elevation }\end{array}$ & $12,5 / 22$ & 2007 year, Monthly \\
\hline & Slope & $12,5 / 22$ & 2007 year, Monthly \\
\hline & Exposure & $12,5 / 22$ & 2007 year, Monthly \\
\hline & Curvature & $12,5 / 22$ & 2007 year, Monthly \\
\hline & TPI & $12,5 / 22$ & 2007 year, Monthly \\
\hline & $\begin{array}{l}\text { Water- } \\
\text { surface area }\end{array}$ & $10 / 15$ & Monthly, Monthly \\
\hline & $\begin{array}{l}\text { Dam site } \\
\text { width }\end{array}$ & $10 / 15$ & Monthly, Monthly \\
\hline \multirow{4}{*}{ 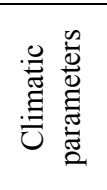 } & $\begin{array}{l}\text { Earth's surf. } \\
\text { temp. }\end{array}$ & $1000 / 30$ & Daily, Monthly \\
\hline & Precip. rate & 50 & Daily \\
\hline & Snow cover & $500 / 15$ & Daily, Monthly \\
\hline & Snow depth & 5000 & Daily \\
\hline
\end{tabular}

\subsection{ERS integration in HPP regimes modeling}

Using geographic and climatic data, it must be taken into account that most of them are three-dimensional matrices containing in total millions of parameter values, and it is not possible to use them in their original form for most algorithms and mathematical models. In addition, the initial data and their sources are selected in such a way that for each of the criteria and for each analyzed section of the area it was possible to obtain a number of retrospective values. Thus, we obtain the analyzed data presented in the form of four-dimensional matrices. Therefore, in the study, it is necessary to consider and analyze possible ways of reducing the dimension of each of the parameters and taking into account the past values of the parameters (in the form of the values themselves, the rate of change, the difference between the forecast and true values, etc.).

GIS monitoring data provide accurate and up-to-date information on the hydrological, hydrographic, and climatic parameters of the river with a high refresh rate. At the design stage, the use of GIS technology will increase the accuracy of calculating the design parameters of HPPs and reservoir capacity. During the operation of a HPP, the use of an ERS database will increase the accuracy of predicting the natural inflow to the HPP site, as well as losses caused by natural factors. A list of possible tasks solved on the basis of ERS data is shown in Figure 6.

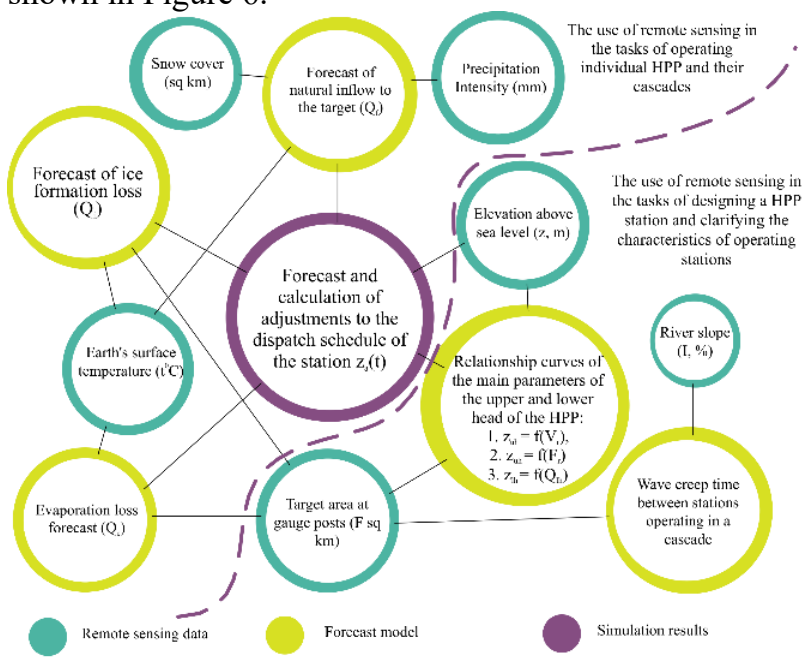

Fig. 6. List of tasks solved on the basis of ERS data.

\section{Result and Discussions}

Let's consider the tasks in more detail.

1. One of the most important tasks at the stage of HPP designing is to determine the useful volume of a plant's reservoir.

The parameters of the reservoir directly depend on the terrain, and its area can extend to hundreds of $\mathrm{km}^{2}$. Using satellite information is faster, has a greater coverage of the territory and often more accurately than traditional methods allows determining the reservoir flood zone and calculating its characteristics.

The use of GIS technologies will automate the constructing a correlation curve between the level of the upstream (the mark of the height of the water level in HPP site) and the volume (surface) of the reservoir. This curve describes the dynamics of changes in water reserves and the level of the HPP upstream. The volume of water that is pumped or stored in the reservoir determines the level of water flow through the HPP, which leads to a change in power and the amount of electricity generated. The HPP operation without a 
predetermined curve between the level of the upstream and the volume of the reservoir is impossible.

Similarly, a correlation curve between the downstream level and the flow rate can be constructed. An example of the correlation curves of the upstream and downstream is shown in Figure 7.

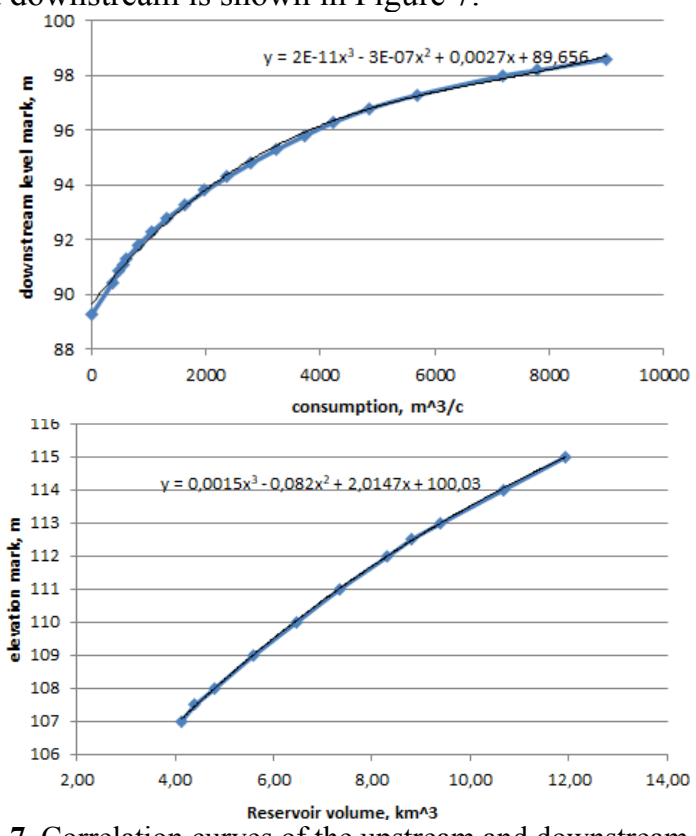

Fig. 7. Correlation curves of the upstream and downstream. Case of Novosibirsk HPP

The solution to the correlation curves tracing is relevant not only for HPP under construction. On the territory of Russia and the CIS countries there are hydroelectric power plants that do not have accurate information about the parameters of their own reservoirs, or reservoirs data has undergone changes over many years of operation. In this case, monitoring of the hydrographic parameters of the alignment will make it possible to correct the data available to the plant staff, which will lead to an increase in the efficiency of controlling plant modes.

2. Data on surface curvature and distance between plants should remain a priority. They can be used to calculate the time it takes for a wave to travel from one plant to another. This will allow more accurate calculation of time corrections in the HPP connected in a cascade operation mode. Formula for calculating the wave travel time:

$$
T_{w}=L / v
$$

where $L-$ distance between first and second plant, $v-$ flow speed.

The flow speed directly depends on the slope of the river and the hydraulic radius of the channel:

$$
v=C \cdot \sqrt{R_{\text {mean }} \cdot J_{\text {mean }}}
$$

where $C$ - speed coefficient, $R_{\text {mean }}$ - average hydraulic radius of the river channel in the area between the cascade HPPs, $J_{\text {mean }}$ - average river slope.
3. At the stage of HPP operation, a special role is given to the tasks of short-term and long-term planning of HPP regimes. The regime planning is based on the forecast of changes in runoff parameters, based on the identification of patterns of change in natural factors within the considered time interval, using the statistical information for the previous stages of observations.

So, based on data on snow cover reserves and temperature changes during the year, a model for predicting inflow to the reservoir site can be constructed. Data on changes in reservoir surface and ambient temperature can be used to calculate evaporation and ice formation losses. To calculate the average water loss for ice formation, you can use the following:

$$
\Delta \bar{Q}_{I}=\gamma_{I} \sum_{i=1}^{n} h_{I i} \cdot\left(F_{N P U}-F_{v b . i}\right) / t_{w}
$$

where $h_{I i}$ - ice depth, $\gamma_{I}=0,9-$ ice density, $F-$ reservoir surface at various elevations, $t_{w}$ - the length of the winter period, determined by the period of the reservoir.

The water losses by evaporation are determined by:

$$
\Delta \bar{Q}_{v}=\sum_{i=1}^{n}\left(h_{w i}-h_{t i}\right) \cdot F_{w i} / t_{v}
$$

where $\left(h_{w i}-h_{t i}\right)$ - an additional evaporation layer, determined by the difference between the evaporation layers from the water surface of the $h_{w i}$ reservoir mirror and from the $h_{t i}$ land surface flooded by the reservoir, $t_{v}$ - evaporation period, usually corresponding to the open channel period.

The data obtained are used to adjust the operating mode of the plant. The algorithm for calculating the operational parameters of the HPP based on the forecast of inflow to the hydroelectric power plant and the requirements of the power system is presented in Figure 8.

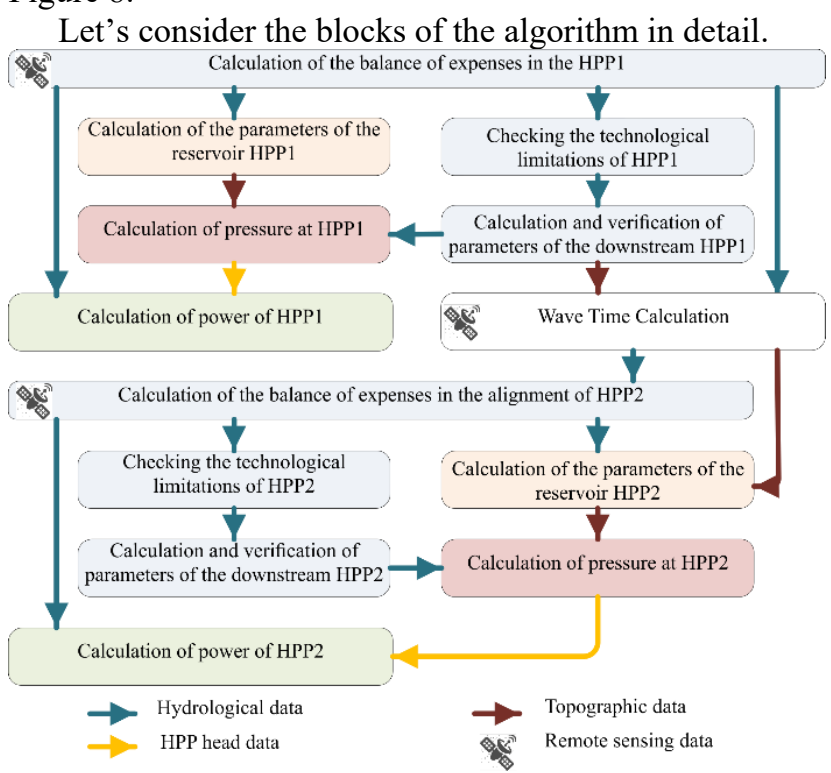

Fig. 8. Algorithm for calculating the water-energy regime of the HPP cascade. 
site"

Block "Expenses balance calculation in the HPP

In this block, the flow rate into the downstream through the hydroelectric turbines and as escapage is calculated, and the flow rate accumulated in the reservoir or taken from it is also set. The calculation is based on data on the natural inflow to the HPP site and flow losses. All described parameters make up the expenses balance in the HPP site:

$$
\begin{gathered}
Q_{h w}(t)=Q_{s}(t) \pm Q_{r}(t)+Q_{r n}(t)- \\
-Q_{v}(t) \pm Q_{i}(t)-Q_{f}(t)-Q_{r k}(t) \\
Q_{t w}(t)=Q_{H P P}(t)+Q_{d r}(t) \\
Q_{d r}(t)=Q_{H P P}(t)-Q_{s}(t) \pm Q_{r}(t) \pm \\
\pm Q_{i}(t)-Q_{f}(t)-Q_{r k}(t)
\end{gathered}
$$

where $Q_{s}$ - natural inflow to the HPP site, $Q_{r}$ reservoir discharge, $Q_{r n}$ - precipitation in the reservoir, $Q_{v}$ - reservoir evaporation, $Q_{i}$ - ice formation losses, $Q_{f}$ filtration flow through the HPP base.

The natural inflow of the underlying station consists of the overlying plant flow, passed through the turbines of the overlying station and side inflow:

$$
Q_{s . H P P 2}(t)=Q_{H P P 1}(t)+Q_{s . s}(t) .
$$

As mentioned above, such parameters as natural inflow, ice formation loss, etc. correlate with climatic parameters in the region. In this regard, it becomes possible to develop balance flow equations for the predicted flow parameters for short and long time periods.

\subsection{Block "HPP technological limitations checking"}

In this block, the HPP flow is checked for compliance with technological and operational constraints.

$$
Q_{n . t w}(t) \leq Q_{H P P}(t) \leq Q_{\max } .
$$

In this equation $Q_{n, t w}(t)$ - the required minimum flow to the HPP downstream to comply with the requirements of water management complex, $Q_{\max }-$ maximum allowable flow rate for technological limitations of the main power equipment. Such as:

Turbine troughput limit.

$$
Q_{\max }=n \cdot Q_{\max T} \cdot \sqrt{H_{i} / H_{p}}
$$

where $Q_{\max T}-$ maximum turbine throughput, $H_{p}-$ rated head, $n$ - number of operating hydraulic units.

Generator installed power limit.

$$
Q_{\max }=n \cdot\left[N_{\text {hurp }} /\left(9,81 \cdot \eta_{T} \eta_{G} \eta_{W S F} \cdot H_{i}\right)\right]
$$

where $N_{\text {hup }}$ - hydraulic unit rated power, $\eta_{T} \eta_{G} \eta_{W S F}$ efficiency of a turbine, generator and water supply facilities, correspondingly.

\subsection{Block "HPP downstream calculation and parameters verification"}

In this block, the downstream elevation is determined depending on the total flow rate passed through HPPs hydraulic units and dam water discharge facilities. The calculation is based on the function shown in Figure 7.

\subsection{Block "HPP reservoir parameters calculation"}

In this block, the upstream elevation is determined depending on the outflow volume. The volume stored in the reservoir is determined by the flow rate $Q_{r}$.

$$
V_{r}=V_{r}(D S L) \pm \int Q_{r} d t .
$$

The calculation is based on the function $Z_{h w} f\left(V_{s}\right)$, shown in Figure 7.

Also in the block compliance with all constraints imposed on the reservoir upstream is checked.

$$
\begin{gathered}
Z_{D S L} \leq Z_{h w} \leq Z_{N W L} \\
Z_{h w \text { Min }} \leq Z_{h w i} \leq Z_{h w \text { Max }}
\end{gathered}
$$

where $Z_{h w \text { Min }}$ - minimum upstream level, due to limited power guaranteed; $Z_{h w M a x}$ - maximum upstream level due to the requirements for the reservoir resources optimal allocation for long-term planning.

\subsection{Block "Pressure calculation in the HPP"}

The HPP pressure is defined as the difference between the level of the upstream and downstream taking into account losses in water supply facilities:

$$
H=Z_{h w}-Z_{t w}-\Delta h .
$$

In the block for pressure calculating for plant No 2 , the time taken to reach the flow rate from the first plant to the second is also taken into account, which directly affects the second plant upstream level.

$$
H_{H P P 2}=Z_{r n . H P P 1}\left(t-T_{a d d}\right)-Z_{r n . H P P 2}(t)-\Delta h_{H P P 2} .
$$

\subsection{Block "HPP power calculation"}

The power calculation is based on the parameters of the HPP flow and pressure, as well as the efficiency of the main power equipment of the plant.

$$
N_{H P P}=9,81 H Q_{H P P} \eta_{T} \eta_{G} \eta_{W S F} .
$$




\subsection{Block "Wave travel time calculation"}

In this block, the time it takes for the wave to travel from the higher HPP 1 to HPP 2 is calculated.

$$
T_{r n}=\frac{L \cdot \sum R_{i} \cdot m+L \cdot m^{2} \cdot n}{0,87 \cdot\left(\sum R_{i}\right)^{\frac{3}{2}} \cdot\left(\sum J_{i}\right)^{\frac{1}{2}}}
$$

where $R_{i}$ и $J_{i}-$ hydraulic radius and slope of the river section. $L$ - distance between HPPs.

The use of a GIS monitoring system allows to accurately determine the geographic parameters of the river channel between plants, which makes it possible to increase the accuracy of the travel time calculation and to exclude the corresponding errors.

\section{Conclusions}

The planning of electric power systems with a large share of hydrogeneration long-term and short-term operation modes is inextricably associated with waterenergy calculation. It is possible to increase the effectiveness of plans with the correct consideration of climatic and geographical parameters through the use of GIS monitoring. Creating a simulation model of a HPP cascade with the ERS integration gives advantages in HPP actual parameters calculating.

\section{References}

1. M. V. Egorov, T. N. Protopopova, Imitative modeling of the operational water-energy balance of HPS of the Volga-Kam cascade. Single grid energy. 1, 40-49 (2013) (In Russian)

2. A. G. Rusina, HPP: The Art of Management. NSTU, Novosibirsk, 214 (2019) (In Russian)

3. X. Wang et al., "Using Remote Sensing to Monitor the Water Change of Xiong'an New Area," International Geoscience and Remote Sensing, Yokohama, Japan, 2019, pp. 4415-4418.
4. J. Zhang et al., "Knowledge representation of remote sensing quantitative retrieval models," 2014 IEEE Geoscience and Remote Sensing Symposium, Quebec City, QC, 2014, pp. 4504-4507.

5. B. L. Fu et al., Study on Accuracy Assessment of dem in the Marsh Using with Interferometric Palsar, SENTINEL-1A and Terrasar- $X$ Images. The Int. Archives of Photogrammetry, Remote Sensing and Spatial Information Sciences, 42, 289-296 (2020)

6. E. Panidi et al., Mapping of the land cover spatiotemporal characteristics in northern russia caused by climate change. International Archives of the Photogrammetry, Remote Sensing \& Spatial Information Sciences, 41, 997-1002 (2016)

7. M. Moscadelli, et al. Temperature-emissivity separation assessment in a sub-urban scenario. Int. Archives of the Photogrammetry, Remote Sensing \& Spatial Information Sciences, 42, 129-136 (2017)

8. M. I. Batchaev, R. G. Zakinyan, Mathematical model of floods with the distributed parameters. The Science. Innovation. Technologies. North Caucasus Federal University, 1, 95-102 (2018) (In Russian)

9. A. T. Zinoviev et al., Forecast and observation of extreme spring and rainfall floods on the upper $\mathrm{Ob}$. Water and environmental problems of Siberia and Central Asia, 76-87 (2017) (In Russian)

10. W. S. Olson, H. Masunaga, The GPM Combined Radar-Radiometer Algorithm Team. GPM Combined Radar-Radiometer Precipitation Algorithm Theoretical Basis Document. (2011)

11. L. S. Kuchment, Problems of selection of flow formation models for solving practical problems. Scientific support for the implementation of the "Water Strategy of the Russian Federation for the period until 2020", 74-80 (2015)

12. D. K. Hall, et al. MODIS/Terra Snow Cover Daily L3 Global 500 m SIN Grid, (2016) 